Brit. J. prev. soc. Med. (1974), 28, 104-107

\title{
Reliability of reporting by women taking part in a prospective contraceptive study
}

\author{
MARTIN P. VESSEY, BRIDGET JOHNSON, AND JAMES DONNELLY* \\ Department of the Regius Professor of Medicine, Radcliffe Infirmary, Oxford OX2 6HE and \\ Health Services Research and Intelligence Unit, Scottish Home and Health Department, Edinburgh EH2 4 YT
}

\section{SUMMARY}

A prospective study is in progress at 17 family planning clinics to try to provide a balanced view of the beneficial and harmful effects of different methods of contraception. During follow-up, data about pregnancies and their outcome, hospital visits, and changes in contraceptive practices are collected from the participants in the study at routine clinic visits, by postal questionnaire, or by home visiting. Whenever a hospital admission is reported, a copy of the discharge letter or summary is obtained.

In the present investigation, the reliability of reporting of pregnancies and their outcome and hospital admissions by 1,915 subjects attending two Scottish clinics was checked by comparing information obtained by the routine survey methods with maternity and hospital inpatient records maintained by the Scottish Home and Health Department. It was found that no births, miscarriages, terminations of pregnancy or admissions for sterilization had been missed in the prospective study while $90 \%$ of all other hospital admissions were reported. No evidence was obtained of any important variation in the reliability of reporting between users of different methods of contraception or between different methods of collecting the follow-up information.

\section{INTRODUCTION}

In 1968, a prospective study was started in certain clinics run by the Family Planning Association to try to provide a balanced view of the beneficial and harmful effects of different methods of contraception. This investigation, which is co-ordinated by the Department of the Regius Professor of Medicine at Oxford, is now in progress at 17 clinics, and over 16,000 women are under observation.
For a clinic patient to be eligible for recruitment to the study she has to be (a) aged 25-39 years, (b) married, (c) a white British subject, (d) willing to participate, and (e) either a current user of oral contraceptives of at least five months' standing or a current user of the diaphragm or an intrauterine device of at least five months' standing without prior exposure to oral contraceptives. During follow-up each subject is questioned at return visits to the clinic by a doctor or a nurse, and entries are made on a special form which enable a record of pregnancies and their outcome, hospital visits, changes in contraceptive methods, and results of cervical smears taken at the clinic to be accumulated. Women who default are sent a postal version of the follow-up form and, if this is not returned, are visited in their homes for collection of the necessary information.

Data relating to hospital admissions are the principal source of information about morbidity in this study. For this reason, whenever a hospital admission is reported, contact is made with the consultant concerned and a copy of the discharge summary or letter is obtained.

From the above it will be clear that the basic source of information in this study is the woman herself. This situation immediately raises questions about the reliability of the data collected. Furthermore, because women using different methods of contraception have different patterns of clinic attendance (for example, those using oral contraceptives are usually seen every three to six months while those using the diaphragm or an intrauterine device are usually seen every six to 12 months), the possibility of bias in reporting between the three contraceptive groups must also be considered.

Fortunately, two of the family planning clinics participating in the study are situated in Scotland. This has enabled us to use the maternity and 
hospital inpatient records maintained by the Scottish Home and Health Department to assess the reliability of information collected about pregnancies and their outcome and hospital admissions from the women recruited to the study at these two clinics. Our findings are the subject of the present report.

\section{Methods}

Identifying information (surname, initials, and date of birth) relating to each of the 1,915 subjects recruited to the prospective study at the two Scottish clinics between 1 November 1969 (the starting date of the study at these clinics) and 31 December 1971 was extracted from the index of participants. Maternities and hospital admissions experienced by these women during the years 1969-71 inclusive were then identified and listed by a search of the appropriate data files held by the Scottish Home and Health Department. Only those records where the degree of certainty of a correct match was high were considered for the present purpose. The lists were then compared with the information collected, as already described, during the course of the prospective study. During this procedure, events occurring before the date of recruitment of each subject to the prospective study were, of course, ignored. It should also be noted that where two or more hospital admissions for the same disease (as defined by the three-digit International Classification of Disease number) were listed for a subject during the follow-up period, only the first such admission was compared with the data collected during the prospective study. This restriction was imposed because all analyses of morbidity in the prospective study are based on 'first events'; repeat admissions for the same disease are therefore of no special interest.

Careful precautions were taken to ensure that confidentiality was maintained during this exercise. First, the identifying information w'as made available by the Department of the Regius Professor of Medicine to the Scottish Home and Health Depart. ment on the strict understanding that it would be used only for the purpose already described. Secondly, the Department of the Regius Professor of Medicine undertook to make no approach to any woman about whom previously unknown information was discovered without first referring the matter back to the Scottish Home and Health Department and to the appropriate consultant. Thirdly, the entire process of comparing the data provided by the Scottish Home and Health Department with the data obtained during the course of the prospective study was carried out by two of us, namely M.P.V., a medically qualified epidemiologist, and B.J., a senior research assistant who has signed an undertaking to maintain confidentiality in accordance with the recommendations of the Medical Research Council (1973).

\section{RESULTS}

One livebirth and two non-obstetrical hospital admissions included on the lists provided by the Scottish Home and Health Department related to women who were lost to follow-up in the prospective study. When the remaining events were compared with the information recorded on the prospective study follow-up forms, a total of 16 hospital admissions which appeared not to have been reported were identified. It occurred to us, however, that

TABLE I

COMPARISON OF EVENTS RECORDED ON THE LISTS PROVIDED BY THE SCOTTISH HOME AND HEALTH DEPARTMENT WITH EVENTS RECORDED IN THE PROSPECTIVE STUDY

\begin{tabular}{|c|c|c|c|c|c|c|c|c|c|c|}
\hline \multirow{3}{*}{\multicolumn{2}{|c|}{ Type of Event }} & \multicolumn{9}{|c|}{ Method of Contraception used by Subject at Entry to Prospective Study } \\
\hline & & \multicolumn{2}{|c|}{ Oral } & \multicolumn{2}{|c|}{ Diaphragm } & \multicolumn{2}{|c|}{$\begin{array}{c}\text { Intrauterine } \\
\text { Device }\end{array}$} & \multicolumn{3}{|c|}{ All Methods } \\
\hline & & $\mathbf{n}^{1}$ & $\mathbf{n}^{2}$ & $\mathrm{n}^{1}$ & $\mathrm{n}^{2}$ & $\mathrm{n}^{1}$ & $\mathrm{n}^{2}$ & $\mathrm{n}^{1}$ & $n^{2}$ & $100 n^{1 / n^{2}}$ \\
\hline \multirow{3}{*}{$\begin{array}{l}\text { Live- or still-birth } \\
\text { Miscarriage or termination } \\
\text { Admission for: } \\
\text { Sterilization } \\
\text { Gynaecological or breast } \\
\text { disease } \\
\text { Psychiatric disease } \\
\text { Any other disease }\end{array}$} & $\because$ & $\begin{array}{r}17 \\
4\end{array}$ & $\begin{array}{r}17 \\
4\end{array}$ & $\begin{array}{r}21 \\
5\end{array}$ & 21 & $\begin{array}{l}6 \\
7\end{array}$ & $\begin{array}{l}6 \\
7\end{array}$ & $\begin{array}{l}44 \\
16\end{array}$ & $\begin{array}{l}44 \\
16\end{array}$ & $\begin{array}{l}100 \\
100\end{array}$ \\
\hline & . & 14 & 14 & 5 & 5 & 7 & 7 & 26 & 26 & 100 \\
\hline & $\because$ & $\begin{array}{r}26 \\
0 \\
26\end{array}$ & $\begin{array}{r}30 \\
1 \\
27\end{array}$ & $\begin{array}{r}16 \\
1 \\
18\end{array}$ & $\begin{array}{r}18 \\
1 \\
19\end{array}$ & $\begin{array}{r}5 \\
0 \\
10\end{array}$ & $\begin{array}{r}6 \\
0 \\
11\end{array}$ & $\begin{array}{r}47 \\
1 \\
54\end{array}$ & $\begin{array}{r}54 \\
2 \\
57\end{array}$ & $\begin{array}{l}87 \\
50 \\
95\end{array}$ \\
\hline $\begin{array}{l}\text { Total, excluding births, } \\
\text { carriages, terminations } \\
\text { sterilizations }\end{array}$ & $\begin{array}{l}\text { mis- } \\
\text { and } \\
. .\end{array}$ & 52 & 58 & 35 & 38 & 15 & 17 & 102 & 113 & 90 \\
\hline
\end{tabular}

$n^{1}=$ number of events on lists from Scottish Home and Health Department which were also recorded on the prospective study follow-up $n^{2}=$ number of events on lists from Scottish Home and Health Department 
some of these 16 admissions might represent incorrect matching rather than failures in reporting. Accordingly, a detailed investigation of these admissions was undertaken by the Scottish Home and Health Department, utilizing comprehensive identification data (including address, name of general practitioner, maiden surname, and National Health Service number) made available by the Department of the Regius Professor of Medicine. This exercise showed that five of the apparent failures in reporting were, in fact, attributable to mis-matching, leaving a total of 11 genuine reporting failures.

Table I shows the main results of the present investigation, discounting the five incorrect matches. No births, miscarriages, terminations of pregnancy or admissions for sterilization were missed in the prospective study, while $90 \%$ of all other hospital admissions were reported. It is, perhaps, noteworthy that only one of the two psychiatric admissions was reported and that a slightly higher proportion of admissions for disorders of the breast or reproductive system was missed than of admissions for other disorders. There was, however, no indication of any important bias in reporting between the different contraceptive groups; thus $90 \%, 92 \%$, and $88 \%$ of the hospital admissions for reasons other than childbirth, miscarriage, termination of pregnancy or sterilization were reported in the oral, diaphragm, and intrauterine device contraceptive groups respectively.

Table II shows a simple analysis of the effect of some additional factors which we thought might be related to the reliability of reporting in the prospective study. The numbers are small, but there is a suggestion of less adequate reporting by women of low social class and of very short admissions. In the present context, however, the most important finding is that the collection of data by questioning at the clinic yielded closely similar results to the collection of data by other means (almost entirely by postal questionnaire).

Table III gives details of the discharge diagnoses given by the Scottish Home and Health Department for the 11 hospital admissions which were not reported in the prospective study. It can be seen that, with the exception of the one psychiatric illness, all the admissions were for minor conditions.

We also examined the relationship between the date of hospital discharge and the date at which the patient was subsequently seen at the clinic or sent a postal questionnaire. We were unable to detect any pattern which might explain why the 11 hospital admissions were not reported.
TABLE II

RELIABILITY OF REPORTING OF HOSPITAL ADMISSIONS FOR REASONS OTHER THAN CHILDBIRTH, MISCARRIAGE, TERMINATION OF PREGNANCY AND STERILIZATION IN RELATION TO CLINIC ATTENDED, METHOD OF
FOLLOW-UP, AGE, SOCIAL CLASS, AND DURATION OF

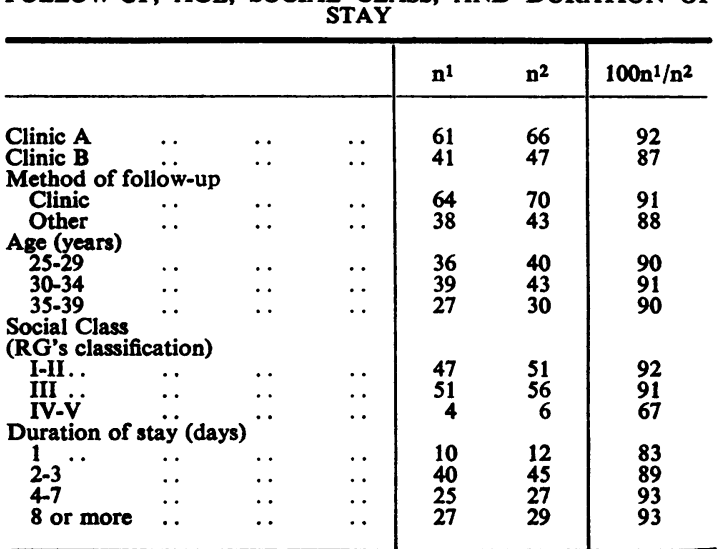

$n^{1}=$ number of events on lists from Scottish Home and Health Department which were also recorded on the prospective study follow-up forms

$n^{2}=$ number of events on lists from Scottish Home and Health Department

TABLE III

DISCHARGE DIAGNOSES PROVIDED BY THE SCOTTISH HOME AND HEALTH DEPARTMENT FOR THE 11 ? ADMISSIONS WHICH WERE NOT REPORTED IN THE

\begin{tabular}{c|l}
\hline ICD No. & \multicolumn{1}{|c}{ Nature of Diagnosis } \\
\hline $298 \cdot 0$ & Reactive depressive psychosis (1) \\
$454 \cdot 9$ & Varicose veins without mention of ulcer (1) \\
$611 \cdot 0$ & Acute mastitis not associated with lactation (1) \\
$620 \cdot 0$ & Chronic cervicitis (1) \\
$621 \cdot 3$ & Chronic erosion and ulceration of cervix (1) \\
$626 \cdot 2$ & Excessive menstruation (2) \\
$626 \cdot 6$ & Intermenstrual bleeding (1) \\
$786 \cdot 0$ & Pain referable to urinary system (1) \\
Y06.0 & Investigation of genital system (1) \\
Y10.0 & General physical examination (1) \\
\hline
\end{tabular}

Assessment of the accuracy of the diagnostic codes in the prospective study was not an objective of the present exercise, since copies of discharge summaries or letters were routinely obtained and coding was subsequently carried out by a doctor. It may be noted, however, that of the 102 hospital admissions for reasons other than childbirth, miscarriage, termination of pregnancy or sterilization represented both on the Scottish Home and Health Department lists and on the prospective study follow-up forms, 72 had been allocated the same three-digit International Classification of Disease list number as the principal diagnosis in both sets of data. Of the remainder, 20 showed only minor discrepancies. Major discrepancies appeared to arise most frequently when incomplete information was available at the time that data were 
abstracted for the Scottish Home and Health Department. For example, one patient with a final diagnosis of carcinoma-in-situ of the cervix (list no. 234.0) was allocated the diagnosis 'investigation of the genital system' (list no. Y060). It would appear that the histological report was not available at the time of preparation of the case abstract for the Scottish Home and Health Department.

\section{Discussion}

As far as the prospective study of women using different methods of contraception is concerned, the results of the present investigation are most encouraging. All births, miscarriages, terminations of pregnancy, and sterilizations recorded by the Scottish Home and Health Department were reported by the survey participants at the two Scottish clinics, while $90 \%$ of other hospital admissions were also reported. Furthermore, no evidence was obtained of any important bias in reporting with respect to method of contraception or method of collecting follow-up information.

To what extent it is possible to generalize the results of this investigation to other situations is uncertain, because the women taking part in the prospective study represent a selected group of volunteers, highly motivated towards family planning. It is of interest, however, to compare the findings with those obtained in a special study undertaken by the United States Health Interview Survey (National Center for Health Statistics, 1965). In this investigation 879 people of both sexes, aged 18 years or more, who were known to have been recent hospital inpatients, were interviewed in their homes and asked about hospital discharges in the preceding year. It was found that $92 \%$ of hospital discharges experienced by the men and $90 \%$ experienced by the women (deliveries excluded) were reported at the home interview. There was little relationship between under-reporting and age among those who were under 65 years old, while the accuracy of reporting increased with family income and educational success. Underreporting was strongly associated with length of stay in hospital; thus for stays of only one day $72 \%$ were correctly reported while for stays of 8 or more days the corresponding figure was $93 \%$. With regard to the nature of the diagnosis, it was concluded that conditions which were embarrassing or 'threatening' were most likely to be under-reportedfor example, only $68 \%$ of psychiatric disorders and
$79 \%$ of disorders of the female breast and genital system were reported. Under-reporting also showed a positive relationship with the number of weeks between discharge and interview. Up to 40 weeks, however, the association was not strong; thereafter it increased sharply, probably because the respondents failed to report an appreciable number of hospital admissions of which they were aware because they were uncertain whether or not they had occurred within the one year recall period.

In general, our findings agree closely with those obtained by the United States Health Interview Survey. The two most notable differences are, first, that disorders of the breast and reproductive system were reported almost as reliably as other conditions in our study and, secondly, that we were unable to detect any relationship between under-reporting and the interval between discharge from hospital and questioning. The first of these differences is not difficult to explain since the participants in our prospective study would not be expected to be as embarrassed by the occurrence of disorders of the breast or reproductive system as women in the general population. The second may be related to the fact that whenever survey participants are questioned at the clinic or sent a postal questionnaire they are requested to report hospital admissions which may have been within the period of recall as well as those about which there is no doubt in their minds. In this way, confusion about admissions occurring around the time of the start of the period of recall, which complicated the interpretation of the Health Interview Survey, seems to have been avoided.

We express our thanks to the Medical Research Council for financial support; to Mrs. D. Collinge and Mrs. S. Jeffreys for careful work in the day to day running of the prospective study; to the research assistants, doctors, and nurses working in the family planning clinics who have made great efforts to collect reliable data; to the staff of the Scottish Office Computer Service for producing the listings of maternities and hospital admissions; and to Dr. M. A. Heasman for advice and encouragement.

\section{REFERENCES}

Medical Research Council (1973). Responsibility in the use of medical information for research. Brit. med. J., 1, 213.

National Center for Health Statistics (1965). Reporting of hospitalization in the Health Interview Survey. US Department of Health, Education and Welfare, Washington D.C. 